\title{
Oligomerization of family B GPCRs: exploration in inter-family oligomer formation
}

\author{
Hans K. H. Ng and Billy K. C. Chow* \\ Department of Endocrinology, School of Biological Sciences, The University of Hong Kong, Hong Kong, China
}

\section{Edited by:}

Hubert Vaudry, University of Rouen,

France

\section{Reviewed by:}

Jae Young Seong, Korea University, South Korea

Alain Couvineau, Institut National de la Santé et de la Recherche Médicale (INSERM), France

\section{*Correspondence:}

Billy K. C. Chow, Endocrinology,

School of Biological Sciences, The

University of Hong Kong, Pokfulam

Road, Hong Kong, China

e-mail:bkcc@hku.hk

\begin{abstract}
G-protein-coupled receptors (GPCRs) are classified into A to F subfamilies in which only families $A, B$, and $C$ are present in mammals. Some of these GPCRs were found to form higher ordered structures such as oligomers with the discovery of interacting receptors in the form of homomers or heteromers. The importance of these oligomers on regulating receptor functions has recently been an intense research focus. It has been proposed that receptor oligomer formation has impact on its physiological importance on receptor trafficking, signaling, ligand-related regulation, and also is related to certain diseases. The present body of knowledge, however, comprises mainly intra-family oligomers formation and their consequences. Inter-family oligomers are recognized but there is limited information. This article aims to provide a current view regarding inter-family GPCR oligomerization in the subfamilies $A, B$, and $C$ found in mammals.
\end{abstract}

Keywords: GPCR, family B, GPCR oligomerization, homomer, heteromer

\section{INTRODUCTION}

The vast structural and functional diversity of G-protein-coupled receptors (GPCRs) makes it the largest membrane receptor family. Members of the GPCR family include receptors responding to hormones, neurotransmitters, lipids, photons, ions, nucleotides, among others (1). It has been 20 years since GPCRs are classified according to the A to F system by Kolakowski in 1994. Under this system, only families A, B, and C are found in mammals (2). For these three families of receptors, rhodopsin-like receptors are classified as family A. Family B is further divided into three subfamilies by Harmar into subfamily B1 (secretin-like receptors), B2 (adhesion family), and B3 (Methuselah-like receptors) (3). Family $\mathrm{C}$ comprises members having characteristic long $\mathrm{N}$ and C-termini and are responsible for sensing metabotropic glutamate, $\mathrm{Ca}^{2+}$ ion, and $\gamma$-aminobutyric acid $(\operatorname{GABA})(4,5)$. The concept of GPCRs oligomerization can be dated back to 1982 when Fraser and Venter discovered that $\beta_{2}$-adrenergic receptors $\left(\beta_{2}-\mathrm{AR}\right)$ form dimers in the cell membrane. Their studies provided the first piece of biophysical evidence of GPCR oligomerization using immunoaffinity chromatography, sodium dodecyl sulfatepolyacrylamide gel electrophoresis (SDS-PAGE), and radiation inactivation techniques (6). Since then, receptor dimerization events were demonstrated by co-immunoprecipitation (co-ip) and resonance energy transfer approaches. Among the first studied cases of GPCRs oligomerization, most effort had been focused on family A GPCRs, while oligomerization in family B GPCRs was largely neglected until Miller's and Schelshorn's groups provided information on such events in the past decade. The Miller's group described the homo-oligomerization of secretin receptor (SCTR) $(7,8)$ and the heteromer formation of SCTR with other family B GPCRs $(8,9)$, while Schelshorn's group described glucagon (GCG), glucagon-like peptide-1 (GLP1), glucagon-like peptide-2 (GLP2), and gastric inhibitory polypeptide (GIP) receptors oligomerization (10-12). Apart from providing biophysical proof of GPCRs interactions, physiological consequences of such interaction were also elucidated in the past 15 years when it was gradually unveiled that oligomerization of receptors plays roles in trafficking, ligand-promoted regulation, ligand binding, allostery, as well as signal transduction (13). There also exist in vivo evidence that dimerization of family B SCTR with family A angiotensin II receptor type $1 \mathrm{a}(\mathrm{AT} 1 \mathrm{aR})$ modulates the signaling properties of the receptors (14). In view of the emerging emphasis on inter-family GPCRs oligomerization and the functional importance of such event, this article will review the basis of GPCRs oligomerization emphasizing on family B GPCRs.

\section{GPCR OLIGOMERIZATION}

G-protein-coupled receptors were originally thought to function as monomeric molecules, with a 1:1 stoichiometry for one receptor protein to interact with one heterotrimeric $G$ protein (13). However, with the advancement in receptor biology research, GPCR homo- and/or hetero-oligomerization is now generally accepted as a common phenomenon. Although the exact stoichiometry of such interaction remains mostly undetermined under the current limitation of technical difficulties, oligomers of GPCRs have proved to involve in vital roles in terms of functioning of the receptors.

For family A GPCRs, evidences have suggested dimerization as a prerequisite for correct trafficking as well as signaling of certain receptors. Examples are somatostatin receptor and adrenergic receptors $(15,16)$. Ligand may also regulate the oligomeric state of receptors on the cell surface, either positively for the luteinizing hormone receptor (17) or negatively for the thyrotropin receptor (18). Ligand binding cooperativity was observed to be altered in M2 muscarinic receptor dimers (19).

For family C receptors, receptor oligomerization is essential to the proper functioning of the protein. A classic example is the $G A B A_{B}$ receptor $\left(G A B A_{B} R\right)$, which is the heterodimer of the 
protomers $G A B A_{B} 1 R$ and $G A B A_{B} 2 R$. The ligand binding site is located on $\mathrm{GABA}_{\mathrm{B}} 1 \mathrm{R}$ but transportation to the cell membrane as well as G-protein coupling for proper functioning of the receptor can only be achieved when $\mathrm{GABA}_{\mathrm{B}} 2 \mathrm{R}$ is present and heterodimerizes with $\operatorname{GABA}_{B} 1 \mathrm{R}(20,21)$. The significance of family $B$ receptors oligomerization will be discussed later in this article.

\section{METHODS TO STUDY OLIGOMERIZATION OF GPCRS}

Traditionally, co-ip was used to study receptor oligomers. Observations of oligomer formation in GPCRs primarily rest upon on this technique since the first report by Hebert et al. (22) describing $\beta 2$-AR receptor dimers (22). However, due to the technical difficulties, methods utilizing the resonance energy transfer between receptors tagged with luminescent or fluorescent proteins have become more popular. In one of the methods, known as bioluminescent resonance energy transfer (BRET), one of the receptor is tagged usually at the C-terminus with the enzyme Renilla luciferase (Rlu), which acts as the donor molecule, while the acceptor receptor is tagged with a yellow or green fluorescent protein (YFP/GFP). The two receptor constructs are co-expressed in vitro, usually in the form of a saturation experiment when a constant amount of the donor molecule is co-transfected with an increasing amount of acceptor receptors. Upon Rlu activation by its specific substrate, light energy from the reaction can be transferred and excite the acceptor fluorescent protein when the two receptors are in a proximity of $<10 \mathrm{~nm}$ apart. This fluorescence of the acceptor emission can then be quantified as an indicator of receptor interactions known as the BRET signal. For specific interaction, the BRET signal will increase with increasing concentration of acceptor receptor, indicated by a saturation curve. Negative control is provided as a linear straight line when the BRET signal is produced by the random collision of tagged receptors. The advantages of using BRET methods over co-ip is that BRET improves resolution and more importantly, enable faster screening of dimerization partners $(23,24)$. Another similar technique replaces the Rlu with a cyan fluorescent protein (CFP), and requires the activation of CFP by laser for resonance energy transfer. This method is known as FRET and eliminates the use of substrate and is primarily useful in applications to study receptor trafficking under the microscope. However, it suffers the disadvantage of having to employ linear unmixing algorithms in the microscope software due to the possible crosstalk of fluorescent signals from the two fluorescent protein tags (25). An improvement to this situation relies on the use of long-lived rare-earth lanthanides energy donors, such as europium. This time-resolved FRET technique lowers the background signal and hence a higher signal:noise ratio can be obtained over normal FRET procedures (26). Other fluorescent based technologies include bimolecular fluorescence complementation and bimolecular luminescence complementation. These experiments use receptors tagged with a part of the fluorescent/luminescent protein that, upon receptor oligomerization, can reassemble into functional protein again (27). Although there exist different approaches to probe for receptor oligomers, most experimental evidence of the physiological consequences of these GPCRs interactions were only found in the in vitro model. In vivo evidence was poorly lacking until the demonstration of the phenotypes of luteinizing hormone receptor transgenic mice in
2010 (17), and water homeostasis effect of angiotensin II (ANGII) and SCTR homomers and heteromers in 2014 (14).

\section{OLIGOMERIZATION OF FAMILY B GPCRS AND ITS FUNCTIONAL SIGNIFICANCE}

Among the family B GPCRs, the SCTR is the first member of the family cloned from rat (28) and thus is the most comprehensively studied. Using primarily BRET technique, the Miller group provided evidences on SCTR homodimerization $(8,29,30)$, as well as heterodimer formation with glucagon-like peptide-1 receptor (GLP1R), glucagon-like peptide-2 receptor (GLP2R), vasoactive intestinal peptide receptors 1 and 2 (VPAC1R, VPAC2R), growth hormone-releasing hormone receptor (GHRHR), parathyroid hormone 1 receptor (PTHR1), parathyroid hormone 2 receptor (PTHR2), and calcitonin receptor-like receptor (CRLR) (8, 9). The specific sites of interaction of SCTR homodimer were the transmembrane 4 of the receptor in which Gly243 and Ile247 residues play a key role (29).

For other members of the family, intra-family homomers includes GLP1R, GLP2R, gastric inhibitory polypeptide receptor (GIPR), glucagon receptor (GCGR) (10-12), PTHR1 (31), VPAC1R, VPAC2R (8), GHRHR (32), calcitonin receptor (CALCR) (33), CRLR (34), corticotrophin-releasing hormone receptor 1 (CRHR1) $(35,36)$, and pituitary adenylate cyclaseactivating polypeptide type I receptor (PAC1) (37), while intrafamily heteromers include VPAC1R/VPAC2R (8), GLP1R/GIPR, GLP1R/GCGR, GLP1R/GLP2R, GCGR/GIPR, GCGR/GLP2R, and GIPR/GLP2R (10-12).

For the family B receptors, physiological relevance of dimerization was mainly demonstrated by in vitro experiments. First being the dominant negative effect of a mis-spliced SCTR on wildtype SCTR, leading to gastrinoma development (7). The importance of dimerization for receptor trafficking is observed both in SCTR and VPAC1R in which non-dimerizing receptor constructs failed to reach the cell surface $(8,29,30)$.

Although no effect was observed for SCTR homodimers (8), ligand binding can negatively affect dimer formation of VPAC1R/VPAC2R/PTHR1 homo/heterodimers $(8,9,31)$. Interestingly, GLP1 can positively affect dimer formation for GLP1R and GIPR dimer, while GIP has inhibitory effect on the heterocomplex formation $(12,38)$. In addition to ligand affecting dimer formation, formation of dimer has an effect on ligand binding as well. Using transmembrane domain 4 (TM4) peptide to disrupt GLP1R homodimer formation, binding of the ligand GLP1 (7-36)-NH2 can be nullified (39). Truncated GHRHR can also lead to conformational change in the dimer complex, which is responsible for the inhibition of GHRH ligand binding (32).

Most family B GPCRs elicit their functions through the cAMP and/or phospholipase C (PLC) signaling cascade. The effect of oligomerization on the cellular mobilization of cAMP and calcium was also one of the research areas in GPCR oligomerization studies. In 2007, it was found that by disrupting SCTR homodimer formation using TM4 peptide, cAMP production is reduced (29). GLP1R and GIPR dimer is also known to decrease the maximal responses of GLP1R in terms of $\beta$-arrestin recruitment and calcium mobilization $(38,39)$. Taken together, oligomerization of GPCRs plays vitally important roles on multiple aspects of cell 
physiology. Table 1 outlines the intra-family oligomerization of family B GPCRs, the techniques involved and the physiological significance included.

\section{INTER-FAMILY GPCRS OLIGOMERIZATION}

Since the maturation of the concept of GPCR oligomerization, its functional implications are gradually understood and appreciated. Experimental evidences on oligomer formation as well as physiological importance has been accumulating first in families A and C, then in family B members in the past years. However, most studies so far has been focusing on intra-family receptor oligomerization, inter-family events are poorly understood. The fact that there exist little sequence homology between families A, B, and C receptors, despite having shared common general morphology, may explain this scarcity of information $(5,40)$. Up till now, documented interfamily events include family B GIPR with family A members $\beta_{2}$-AR and opsin. In their experiment, they use the BRET method in a heterologous expression system to discover that cAMP production is increased upon ligand stimulation compared to monomers (41). Family B CRHR1 with family A vasopressin receptor $1 \mathrm{~b}$ (V1bR) was studied again using the BRET technique but instead of tagging the receptors at the $\mathrm{C}$-termini, they are tagged at the $\mathrm{N}$-termini (36). Family B GCGR with family A cholecystokinin A receptor was also reported (CCKAR) (10). Among these, family B SCTR with family A ATlaR shows the most convincing evidence. Based on the observation that both drinking behavior and vasopressin expression and release are impaired in secretin (SCT) or SCTR knockout mice upon intracerebroventricular (i.c.v.) injection of ANGII (42), it was deduced that a SCT/SCTR axis is essential to the proper functioning of ANGII in the central nervous system. With the coexpression of AT1aR and SCTR in the paraventricular nucleus, receptor heterocomplex formation was hypothesized to

Table 1 | Oligomerization of intra-family family B GPCRs

\begin{tabular}{|c|c|c|c|}
\hline Oligomer & Technique & Physiological significance & Reference \\
\hline \multicolumn{4}{|l|}{ HOMOMERS } \\
\hline SCTR/SCTR & BRET/FRET & $\begin{array}{l}\text { Relation with gastrinoma; } \\
\text { promotes cAMP response }\end{array}$ & Ding et al. (7), Harikumar et al. $(8,29)$ \\
\hline GLP1R/GLP1R & BRET & Promotes ligand binding & $\begin{array}{l}\text { Orgaard (10), Roed (11), Schelshorn et al. (12), } \\
\text { Harikumar et al. (39) }\end{array}$ \\
\hline GLP2R/GLP2R & BRET & N/A & Schelshorn et al. (12) \\
\hline GIPR/GIPR & BRET & N/A & Schelshorn et al. (12) \\
\hline GCGR/GCGR & BRET & N/A & Orgaard (10), Roed (11), Schelshorn et al. (12) \\
\hline PTHR1/PTHR1 & BRET/FRET & Ligand reduces oligomerization & Pioszak et al. (31) \\
\hline VPAC1R/NPAC1R & Co-ip/BRET/FRET & Ligand reduces oligomerization & Harikumar et al. (8) \\
\hline VPAC2R/NPAC2R & BRET/FRET & Ligand reduces oligomerization & Harikumar et al. (8) \\
\hline GHRHR/GHRHR & Co-ip & Promotes ligand binding & McElvaine and Mayo (32) \\
\hline CALCR/CALCR & Co-ip/BRET/FRET & Alters receptor trafficking & Seck et al. (33) \\
\hline CRLR/CRLR & Co-ip/BRET/FRET & $\mathrm{N} / \mathrm{A}$ & Heroux et al. (34) \\
\hline CRHR1/CRHR1 & FRET/BRET & N/A & Kraetke et al. (35), Young et al. (36) \\
\hline PAC1/PAC1 & Time-resolved FRET & N/A & Maurel et al. (37) \\
\hline \multicolumn{4}{|l|}{ HETEROMERS } \\
\hline SCTR/GLP1R & BRET & N/A & Harikumar et al. (9) \\
\hline SCTR/GLP2R & BRET & N/A & Harikumar et al. (9) \\
\hline SCTR/NPAC1R & FRET/BRET & Receptor trafficking & Harikumar et al. $(8,9,29)$ \\
\hline SCTR/NPAC2R & FRET/BRET & Receptor trafficking & Harikumar et al. $(8,9,29)$ \\
\hline SCTR/GHRHR & BRET & N/A & Harikumar et al. (9) \\
\hline SCTR/PTHR1 & BRET & Ligands reduce oligomerization & Harikumar et al. (9) \\
\hline SCTR/PTHR2 & BRET & Ligands reduce oligomerization & Harikumar et al. (9) \\
\hline SCTR/CRLR & BRET & $\mathrm{N} / \mathrm{A}$ & Harikumar et al. (9) \\
\hline GCGR/GLP1R & BRET & N/A & Orgaard (10), Roed (11), Schelshorn et al. $(12,38)$ \\
\hline GCGR/GLP2R & BRET & None & Schelshorn et al. $(12,38)$ \\
\hline GCGR/GIPR & BRET & None & Schelshorn et al. $(12,38)$ \\
\hline GIPR/GLP1R & BRET & $\begin{array}{l}\text { GLP-1 induces oligomerization and flattened } \\
\mathrm{Ca}^{2+} \text { response; GIP reduces oligomerization } \\
\text { but does not alter } \mathrm{Ca}^{2+} \text { response }\end{array}$ & Harikumar et al. (39), Schelshorn et al. $(12,38)$ \\
\hline GIPR/GLP2R & BRET & None & Schelshorn et al. $(12,38)$ \\
\hline GLP1R/GLP2R & BRET & $\mathrm{N} / \mathrm{A}$ & Orgaard (10), Roed (11), Schelshorn et al. $(12,38)$ \\
\hline VPAC1R/NPAC2R & Co-ip/BRET & Ligand reduces oligomerization & Harikumar et al. (8) \\
\hline
\end{tabular}

Technique involved and physiological significance are described; N/A, information not available. 
be the reason behind this observation. By using BRET techniques, it was found that SCTR interacts with AT1aR specifically, but not angiotensin II receptor type 2 (AT2R). When the receptors were expressed together in vitro and stimulated with SCT alone, cAMP response was blunted compared to cells bearing only SCTR or SCTR with the non-dimerizing AT2R. However, cAMP production could be restored when ANGII was also present or when SCTR was co-expressed with a constitutively active mutant AT1aR, but not with the ANGII binding-deficient mutant AT1aR-K199A. Together with the fact that ATlaR cannot stimulate the cAMP signaling pathway, it was concluded that an active conformation of the ATlaR was responsible for regulating SCTR in mediating cAMP responses. In line with previous finding (29), the role of TM peptides on heterocomplex formation was also elucidated. It was found that peptides derived from SCTR's TM 2 and 4 (STM-II/IV), and AT1aR's TM 1 and 4 (ATM-1/4), could inhibit heteromer formation, while only STM-IV or/ATM-4 peptides could suppress the homomers of SCTR or AT1aR, with alanine mutants of these peptides reversing the situation. ATM-1 was chosen to investigate heteromer-specific actions as this peptide is neither capable of disrupting SCTR nor AT1 aR homomer formation. By using these TM peptides as a tool, specifically ATM-1 and its mutant counterpart, it was demonstrated that full activity of SCT-stimulated SCTR requires the activation of $\mathrm{AT} 1 \mathrm{aR}$ as a prerequisite. To further investigate the physiological relevance of SCTR/AT1aR heteromer in relation to water homeostasis, i.c.v. injections of the TM peptides and their mutants were administered to mice under hyperosmolality stress. All the four aforementioned TM peptides can suppress drinking behavior of these mice under hyperosmolality to different degrees. Of which, STM-IV, ATM-1, and ATM-4 can inhibit drinking behavior to a level similar to that of SCTR knockout mice or mice injected with the protein kinase A inhibitor $\mathrm{H} 89$, for the case of STM-II the effect was not as prominent. These results were reversed when the alanine mutants TM peptides were used instead. The experiments demonstrate that receptor heterocomplex of SCTR and AT1aR plays a role in regulating water drinking behavior in vivo. Furthermore, i.c.v. injection of a combination of low doses of both SCT and ANGII produces an effect on drinking behavior comparable to injection of high doses of these hormones alone, which is significantly greater than that when the hormones were given singly at low doses. This synergistic effect of the hormones in the central nervous system hints that the physiological effect of SCTR can be prominently enhanced with ANGII. This important study strongly suggests the significance of inter-family heterodimer formation on physiology (14). Table 2 summaries the heteromer formation of inter-family GPCRs.

\section{CONCLUSION AND FUTURE PERSPECTIVE}

Since there is a growing body of evidences on the functional importance of GPCR oligomerization but information on potential oligomerizing partners within families $\mathrm{A}, \mathrm{B}$, and $\mathrm{C}$ is lacking; the area of GPCRs oligomerization within these families is being explored in our laboratory recently. Initial approach includes setting up a GPCR-YFP library with GPCRs tagged with YFP. Using this scheme, any GPCR having tagged with Rlu can be screened against this library for oligomer partners. Not only can this study compensate our current paucity of information on inter-family
Table 2 | Oligomerization of inter-family family B GPCRs

\begin{tabular}{|c|c|c|c|}
\hline Heteromers & Technique & $\begin{array}{l}\text { Physiological } \\
\text { significance }\end{array}$ & Reference \\
\hline GIPR/B2-AR & BRET & $\begin{array}{l}\text { Potentiates cAMP } \\
\text { responses }\end{array}$ & Vrecl et al. (41) \\
\hline GIPR/opsin & BRET & $\begin{array}{l}\text { Potentiates cAMP } \\
\text { responses }\end{array}$ & Vrecl et al. (41) \\
\hline CRHR1N1bR & BRET & $\mathrm{N} / \mathrm{A}$ & Young et al. (36) \\
\hline GCGR/CCKAR & BRET & N/A & Orgaard (10) \\
\hline SCTR/AT1aR & BRET/FRET & $\begin{array}{l}\text { Reduces secretin's cAMP } \\
\text { response; alters drinking } \\
\text { behavior }\end{array}$ & Lee et al. (14) \\
\hline
\end{tabular}

Technique involved and physiological significance are described; N/A, information not available.

GPCR oligomers but also the cellular co-localization of these partners and their physiological relevance can be elucidated. If the receptors are found to be co-localized and serving similar functions, further biochemical analysis can be made to assay for the functional significance of the receptor interaction. As such, a number of novel mechanisms in controlling cellular activities may be discovered. Such discoveries could in turn facilitate the development of biochemical tools for scientific research or in vitro diagnostics. As around $30-40 \%$ of the pharmaceutical drugs at present are targeting GPCRs, this basic research on the role of GPCR oligomerization may pave the path for developing pharmaceutical precursors, which may eventually become the answers to a variety of diseases.

\section{ACKNOWLEDGMENTS}

This project was supported by the Hong Kong Government RGC grants HKU 765011M, 764812M, 765113M, and HKU6/CRF/11G to Billy K. C. Chow.

\section{REFERENCES}

1. Bockaert J, Pin JP. Molecular tinkering of G protein-coupled receptors: an evolutionary success. EMBO J (1999) 18:1723-9. doi:10.1093/emboj/18.7.1723

2. Kolakowski LF Jr. GCRDb: a G-protein-coupled receptor database. Receptors Channels (1994) 2:1-7.

3. Harmar AJ. Family-B G-protein-coupled receptors. Genome Biol (2001) 2:reviews3013. doi:10.1186/gb-2001-2-12-reviews3013

4. Kristiansen K. Molecular mechanisms of ligand binding, signaling, and regulation within the superfamily of G-protein-coupled receptors: molecular modeling and mutagenesis approaches to receptor structure and function. Pharmacol Ther (2004) 103:21-80. doi:10.1016/j.pharmthera.2004.05.002

5. Kenakin T, Miller LJ. Seven transmembrane receptors as shapeshifting proteins: the impact of allosteric modulation and functional selectivity on new drug discovery. Pharmacol Rev (2010) 62:265-304. doi:10.1124/pr.108.000992

6. Fraser CM, Venter JC. The size of the mammalian lung beta 2-adrenergic receptor as determined by target size analysis and immunoaffinity chromatography. Biochem Biophys Res Commun (1982) 109:21-9. doi:10.1016/0006-291X(82) 91560-1

7. Ding WQ, Cheng ZJ, McElhiney J, Kuntz SM, Miller LJ. Silencing of secretin receptor function by dimerization with a misspliced variant secretin receptor in ductal pancreatic adenocarcinoma. Cancer Res (2002) 62:5223-9.

8. Harikumar KG, Morfis MM, Lisenbee CS, Sexton PM, Miller LJ. Constitutive formation of oligomeric complexes between family B G protein-coupled vasoactive intestinal polypeptide and secretin receptors. Mol Pharmacol (2006) 69:363-73. doi:10.1124/mol.105.015776 
9. Harikumar KG, Morfis MM, Sexton PM, Miller LJ. Pattern of intra-family hetero-oligomerization involving the G-protein-coupled secretin receptor. J Mol Neurosci (2008) 36:279-85. doi:10.1007/s12031-008-9060-z

10. Orgaard A. Binding and Dimerization Studies on the Glucagon Receptor. Copenhagen: University of Copenhagen (2011).

11. Roed SN. Receptor Dimerization and Binding Profile of the Incretin Glucagon-Like Peptide-1. Copenhagen: University of Copenhagen (2011).

12. Schelshorn DW, Joly F, Mutel S, Hampe C, Breton B, Mutel V, et al. Lateral allosterism in the glucagon receptor family: GLP-1 induces GPCR heteromer formation. Mol Pharmacol (2011) 81:309-18. doi:10.1124/mol.111.074757

13. Terrillon S, Bouvier M. Roles of G-protein-coupled receptor dimerization. EMBO Rep (2004) 5:30-4. doi:10.1038/sj.embor.7400052

14. Lee LTO, Ng SYL, Chu JYS, Sekar R, Harikumar KG, Miller LJ, et al. Transmembrane peptides as unique tools to demonstrate the in vivo action of a cross-class GPCR heterocomplex. FASEB J (2014) 28:2632-44. doi:10.1096/fj.13-246868

15. Venter JC, Horne P, Eddy B, Greguski R, Fraser CM. Alpha 1-adrenergic receptor structure. Mol Pharmacol (1984) 26:196-205.

16. Rocheville M, Lange DC, Kumar U, Sasi R, Patel RC, Patel YC. Subtypes of the somatostatin receptor assemble as functional homo- and heterodimers. J Biol Chem (2000) 275:7862-9. doi:10.1074/jbc.275.11.7862

17. Vassart G. An demonstration of functional G protein-coupled receptor dimers. Proc Natl Acad Sci U S A (2010) 107:1819-20. doi:10.1073/pnas.0914432107

18. Latif R, Graves P, Davies TF. Ligand-dependent inhibition of oligomerization at the human thyrotropin receptor. J Biol Chem (2002) 277:45059-67. doi:10.1074/jbc.M206693200

19. Redka DS, Heerklotz H, Wells JW. Efficacy as an intrinsic property of the M2 muscarinic receptor in its tetrameric state. Biochemistry (2013) 52:7405-27. doi:10.1021/bi4003869

20. Galvez T, Duthey B, Kniazeff J, Blahos J, Rovelli G, Bettler B, et al. Allosteric interactions between GB1 and GB2 subunits are required for optimal GABA(B) receptor function. EMBO J (2001) 20:2152-9. doi:10.1093/emboj/20.9.2152

21. Comps-Agrar L, Kniazeff J, Norskov-Lauritsen L, Maurel D, Gassmann M, Gregor $\mathrm{N}$, et al. The oligomeric state sets GABA (B) receptor signalling efficacy. EMBO J (2011) 30:2336-49. doi:10.1038/emboj.2011.143

22. Hebert TE, Moffett S, Morello JP, Loisel TP, Bichet DG, Barret C, et al. A peptide derived from a beta2-adrenergic receptor transmembrane domain inhibits both receptor dimerization and activation. J Biol Chem (1996) 271:16384-92. doi:10.1074/jbc.271.27.16384

23. Hamdan FF, Percherancier Y, Breton B, Bouvier M. Monitoring proteinprotein interactions in living cells by bioluminescence resonance energy transfer (BRET). Curr Protoc Neurosci (2006) 5(Unit 5):23. doi:10.1002/0471142301. ns0523s34

24. Pfleger KDG, Eidne KA. Illuminating insights into protein-protein interactions using bioluminescence resonance energy transfer (BRET). Nat Methods (2006) 3:165-9. doi:10.1038/nmeth841

25. Ayoub MA, Pfleger KD. Recent advances in bioluminescence resonance energy transfer technologies to study GPCR heteromerization. Curr Opin Pharmacol (2010) 10:44-52. doi:10.1016/j.coph.2009.09.012

26. Albizu L, Cottet M, Kralikova M, Stoev S, Seyer R, Brabet I, et al. Time-resolved FRET between GPCR ligands reveals oligomers in native tissues. Nat Chem Biol (2010) 6:587-94. doi:10.1038/nchembio.396

27. Vidi PA, Ejendal KF, Przybyla JA, Watts VJ. Fluorescent protein complementation assays: new tools to study $\mathrm{G}$ protein-coupled receptor oligomerization and GPCR-mediated signaling. Mol Cell Endocrinol (2011) 331:185-93. doi:10.1016/j.mce.2010.07.011

28. Ishihara T, Nakamura S, Kaziro Y, Takahashi T, Takahashi K, Nagata S. Molecular cloning and expression of a cDNA encoding the secretin receptor. EMBO J (1991) 10:1635-41.

29. Harikumar KG, Pinon DI, Miller LJ. Transmembrane segment IV contributes a functionally important interface for oligomerization of the class II G proteincoupled secretin receptor. J Biol Chem (2007) 282:30363-72. doi:10.1074/jbc. M702325200
30. Lisenbee CS, Miller LJ. Secretin receptor oligomers form intracellularly during maturation through receptor core domains. Biochemistry (2006) 45:8216-26. doi:10.1021/bi060494y

31. Pioszak AA, Harikumar KG, Parker NR, Miller LJ, Xu HE. Dimeric arrangement of the parathyroid hormone receptor and a structural mechanism for ligandinduced dissociation. J Biol Chem (2010) 285:12435-44. doi:10.1074/jbc.M109. 093138

32. McElvaine AT, Mayo KE. A dominant-negative human growth hormonereleasing hormone $(\mathrm{GHRH})$ receptor splice variant inhibits GHRH binding. Endocrinology (2006) 147:1884-94. doi:10.1210/en.2005-1488

33. Seck T, Baron R, Horne WC. The alternatively spliced deltael3 transcript of the rabbit calcitonin receptor dimerizes with the $\mathrm{Cla}$ isoform and inhibits its surface expression. J Biol Chem (2003) 278:23085-93. doi:10.1074/jbc.M211280200

34. Heroux M, Breton B, Hogue M, Bouvier M. Assembly and signaling of CRLR and RAMP1 complexes assessed by BRET. Biochemistry (2007) 46:7022-33. doi:10.1021/bi0622470

35. Kraetke O, Wiesner B, Eichhorst J, Furkert J, Bienert M, Beyermann M. Dimerization of corticotropin-releasing factor receptor type 1 is not coupled to ligand binding. J Recept Signal Transduct Res (2005) 25:251-76. doi:10.1080/ 10799890500468838

36. Young S, Griffante C, Aguilera G. Dimerization between vasopressin V1b and corticotropin releasing hormone type 1 receptors. Cell Mol Neurobiol (2007) 27:439-61. doi:10.1007/s10571-006-9135-8

37. Maurel D, Comps-Agrar L, Brock C, Rives ML, Bourrier E, Ayoub MA, et al. Cellsurface protein-protein interaction analysis with time-resolved FRET and snaptag technologies: application to GPCR oligomerization. Nat Methods (2008) 5:561-7. doi:10.1038/nmeth.1213

38. Schelshorn D, Joly F, Mutel S, Hampe C, Breton B, Mutel V, et al. Lateral allosterism in the glucagon receptor family: glucagon-like peptide 1 induces G-proteincoupled receptor heteromer formation. Mol Pharmacol (2012) 81:309-18. doi:10.1124/mol.111.074757

39. Harikumar KG, Wootten D, Pinon DI, Koole C, Ball AM, Furness SG, et al. Glucagon-like peptide-1 receptor dimerization differentially regulates agonist signaling but does not affect small molecule allostery. Proc Natl Acad Sci U S A (2012) 109:18607-12. doi:10.1073/pnas.1205227109

40. Vohra S, Chintapalli SV, Illingworth CJ, Reeves PJ, Mullineaux PM, Clark HS, et al. Computational studies of family A and family B GPCRs. Biochem Soc Trans (2007) 35:749-54. doi:10.1042/BST0350749

41. Vrecl M, Drinovec L, Elling C, Heding A. Opsin oligomerization in a heterologous cell system. J Recept Signal Transduct Res (2006) 26:505-26. doi:10.1080/ 10799890600932253

42. Lee VHY, Lee LTO, Chu JYS, Lam IPY, Siu FKY, Vaudry H, et al. An indispensable role of secretin in mediating the osmoregulatory functions of angiotensin II. FASEB J (2010) 24:5024-32. doi:10.1096/fj.10-165399

Conflict of Interest Statement: The authors declare that the research was conducted in the absence of any commercial or financial relationships that could be construed as a potential conflict of interest.

Received: 27 November 2014; accepted: 16 January 2015; published online: 02 February 2015.

Citation: $\mathrm{Ng} \mathrm{HKH}$ and Chow BKC (2015) Oligomerization of family B GPCRs: exploration in inter-family oligomer formation. Front. Endocrinol. 6:10. doi: $10.3389 /$ fendo.2015.00010

This article was submitted to Neuroendocrine Science, a section of the journal Frontiers in Endocrinology.

Copyright (C) $2015 \mathrm{Ng}$ and Chow. This is an open-access article distributed under the terms of the Creative Commons Attribution License (CC BY). The use, distribution or reproduction in other forums is permitted, provided the original author(s) or licensor are credited and that the original publication in this journal is cited, in accordance with accepted academic practice. No use, distribution or reproduction is permitted which does not comply with these terms. 